Article

\title{
Two Stage Analysis of Successful Change Implementation of Knowledge Management Strategies in Energy Companies from Romania
}

\author{
Eduard Gabriel Ceptureanu $^{1, *}$ (D), Sebastian Ion Ceptureanu ${ }^{1}$ (D), Doina I. Popescu ${ }^{1}$ \\ and Liviu Bogdan Vlad ${ }^{2}$ \\ 1 Department of Management, the Bucharest University of Economic Studies, 010374 Bucharest, Romania; \\ sebastian.ceptureanu@man.ase.ro (S.I.C.); doina.popescu@man.ase.ro (D.I.P.) \\ 2 Department of Tourism and Geography, the Bucharest University of Economic Studies, \\ 010374 Bucharest, Romania; liviu.vlad@ase.ro \\ * Correspondence: eduard.ceptureanu@man.ase.ro; Tel.: +40-742-214-578
}

Received: 1 November 2017; Accepted: 21 November 2017; Published: 25 November 2017

\begin{abstract}
The purpose of this paper is to emphasize the effects of knowledge management strategies toward organizational change in Romanian companies from the energy sector. This study explored a new vision to implement these types of organizational changes successfully in companies from the Romanian sector of energy and obtain their early benefits by using knowledge management strategies and also reveal the mediating effect of organizational learning and readiness for change. The results highlighted how energy companies can implement an Enterprise Resource Planning (ERP)-based change effectively through KM strategies. The results are equally valuable for all Romanian organizations that are currently changing their working environment.
\end{abstract}

Keywords: Romanian energy sector; organizational learning; organizational change; knowledge management strategies; demographic analysis

\section{Introduction}

The business world today is changing more rapidly than ever before. Given the increased pressures of changing markets, dynamic technology and global competition, companies from the energy sector are increasingly encountering the need for strategic level transformation [1]. This transformation encompasses all parts of a business, its structure, resources, technology, processes, and its culture. Technological developments, expanding markets, financial constraints, new model businesses, restructuring and mergers, and government legislation are putting pressure to change and organizational dynamics [2]. Success goes to those who can visualize how markets are changing, identify new configurations of service or delivery, and change "the rules of the game." Yet, the process of change is far from easy, and implementing it successfully makes considerable demands on the managers involved. Several studies have found that 70 percent of change efforts are unproductive $[3,4]$. A study highlighted that 90 percent of change programs have failed [5]. Therefore, it is important to investigate how the change initiatives can be successful in the dynamic business world.

Without question, change becomes the life organ of every vital organization. There are numerous factors that cause organizations to change, i.e., competitive advantage, organizational renewal, technological transformation, international standards, globalization, innovation, and performance [6,7]. More or less, organizations opt to change their processes, culture, strategies, and structure to gain the required output [8]. Change is also demanded by the national context to line-up organizations with market demands $[9,10]$. Due to stiff business competition, organizations are continuously adopting change mechanisms to remain alive in the industry [11-13]. Therefore, since its inception, 
organizational change (OC) folds substantial attention from researchers $[8,14,15]$. Universally, cynicism about change is the common factor that influences the success rate of change [16]. Barton and Ambrosini [17] argued that organizational change cynicism (CC) affects OC process adversely. Majorly, organizational CC affects employees and creates resistance toward change [17-19]. Extant literature also suggested that cynicism, if it perseveres long time, can damage the whole change process [20].

OC process has different phases, i.e., change initiation, pre-implementation, execution, and postexecution. Every change phase requires a specific type of knowledge for proper accomplishment [21]. Change initiation needs basic knowledge, pre-implementation requires knowledge to reduce cynicism, the execution phase entails core knowledge, and post-implementation involves knowledge to deal with post-implementation problems [6,22]. These types of knowledge can be captured through learning mechanisms of organizations. There are various studies that emphasize the importance of organizational learning (OL) toward different organizational outcomes [23-27]. Bess et al. [28] emphasized the significance of OL toward change. The knowledge-based view of organizations highlighted OL as the core tool to gain appropriate knowledge for attaining competitive advantage and innovation [29-31]. OL is a source to decrease the organizational CC in organizations by explaining the potential benefits of change to employees. Moreover, learning is equally important to increase the readiness for change (CR) that is ultimately helpful for effective change implementation [32,33]. To effectively grasp the fruits of change and to overcome CC factors, organizations have to prepare themselves at every stage for anticipated changes $[13,28]$.

The efforts made by organizations from the energy sector to initiate and implement a transformational change are heavily dependent on effective preparation that is known as change readiness $(\mathrm{CR})[11,34,35]$. Change readiness (CR) becomes the integral part of planning phase of change as it has to address what type of organizational resources are needed for initiation of change and what type of individual and group level reforms are required to implement change [36,37]. Contemporary literature explained that if CR is not addressed properly, it will lead to failure of the whole change process [34,38-40]. Likewise, [41,42] explain that readiness for change effectively addresses the change-related challenges, i.e., developing need for change, modify individual behaviour toward change, making strategies to implement change, and arrangement of appropriate resources to implement change.

For effective change implementation, change agents perform the key role, and their knowledge level determines their intellectual capacity to execute a change process $[43,44]$. On the other hand, the ways that they disseminate change process information is also important. There are two main ideas on how to disseminate information: person to person and person to document [45]. The first strategy is regarded as a personalization knowledge management (KM) strategy in which change agents adopt socialization aspects and communicate information individually or in a group [46-48]. OL can be enhanced through effectively utilizing these KM strategies, i.e., personalization and codification [49,50]. Moreover, these strategies, in combination with organizational learning (OL), are beneficial for developing readiness for change.

The term organizational learning (OL) was first explored by [51] as the outcome of keen observation. OL is further explained by [52], which states that it is all about the learned behaviours and their interpretation. Today, with the advancement of technology, web-based applications, and social networking, OL has many stems except of traditional learning, i.e., web 2.0 learning, vicarious learning, social learning, and strategic learning $[24,53,54]$. There is evidence in the existing literature that OL positively affects different organizational outcomes, i.e., innovative ability, organizational renewal, strategic vision, problem solving, initiating and implementing change, competitive advantage, managerial effectiveness, and overall performance $[21,23,55,56]$. Without question, OL sets the basis of sustained and rapid performance in the high-tech business industry where change is ever demanded $[25,57,58]$. In the past, researchers have explored OL as a normal course of activity that is not context specific $[43,59]$. Additionally, socialization aspects give a new shape to learning and 
increase its effectiveness [43,60]. Leaders are currently developing the capabilities of their teams through intensive learning sessions [61,62].

Our paper shows a high level of innovation and novelty, because even if there are studies of change management [63-65], organizational learning [66-68], or knowledge management [69], none of them has the interdisciplinary, coherent approach of our research.

The above discussion indicates that KM strategies, OL, CR, and change have a positive association with each other, but there is very scarce literature available that explains their empirical investigation $[49,70]$. To fill the stated gap, the current study attempts to examine the indirect effect of KM strategies on OC through OL and readiness for change in Romanian companies from the energy sector. Moreover, this study also profiles the interactive effect of organizational CC among OL, CR, and successful organizational change. This is a novel attempt to implement change without pain by utilizing the benefits of KM strategies.

\section{Literature Review}

\subsection{General Energy Policy Framework in the European Union}

By creating the Energy Union, the EU aims to stimulate economic growth, guarantee European energy security, and combat climate change. The objective of the energy policy package is to ensure affordable, safe, and sustainable energy for European Union citizens. Five key areas, including energy security, energy efficiency, and carbon reduction, are the subject of specific measures.

At present, the EU is the world's largest energy importer, accounting for $53 \%$ of the annual energy requirement at an annual cost of around $€ 400$ billion [71]. Many EU Member States rely on a limited number of suppliers, especially gas supplies. This makes them vulnerable to disturbances in the supply of energy. Also, Europe's outdated energy infrastructure (especially in Central and Eastern Europe), poorly integrated energy markets-especially cross-border-as well as the lack of coordination of national energy policies often results in EU consumers and businesses having less choice or lower energy prices. The modernization and diversification of energy infrastructure contributes to reducing disturbances and energy dependence on external suppliers. The completion of the internal energy market will allow access to energy markets across national borders, which also facilitates the strengthening of regional cooperation between the Member States of the Energy Union on the one hand and third-party countries on the other [72]. This aspect also improves energy accessibility and the competitiveness of energy prices for consumers. In line with the EU targets set out in the EC Communication on Climate and Energy for 2030, the EU is working to reduce greenhouse gas emissions and overall dependency on fossil fuels. The Framework Strategy is based on the principles of the Climate and Energy Framework for 2030 and the Energy Security Strategy launched in 2014, integrating diverse policy areas into a unitary approach. Thus, three main objectives of the EU's energy policy are contained in the Communication on the Energy Strategy Framework Strategy [73].

\subsection{Romania's Energy Reform Commitments}

For the energy sector, the National Reform Program includes commitments to reduce greenhouse gas emissions, increase the share of renewable energy sources in gross final consumption of energy and energy efficiency (reduction of primary energy consumption), as follows [71]:

- Reducing greenhouse gas emissions by $19 \%$ in 2020 compared to 2005;

- Share of renewable energies in final energy consumption to be $24 \% 2020$;

- Lower primary energy consumption by $19 \%$ in 2020 compared to 2007 PRIMES forecast.

According to Romania's Country Report for 2015, at national level, progress toward achieving the Europe 2020 targets is as follows [71]:

- Romania is on track to reach two Europe 2020 national targets. As far as greenhouse gas (GHG) emissions are concerned, according to the available data from the National Inventory 
of Greenhouse Gas Emissions, the total emissions (including LULUCF, Land Use Change, and Forestry) decreased by 56.02\% between 1990 and 2012 (from 223.43 million tonnes of $\mathrm{CO}_{2}$ equivalent to 98.27 million tonnes of $\mathrm{CO}_{2}$ equivalent). GHG emissions from non-ETS sectors (not covered by GHG emissions trading scheme-EU ETS) decreased by $0.77 \%$ between 2005 and 2012 (from 71.34 million tons of $\mathrm{CO}_{2}$ equivalent to 70.79 million tonnes of $\mathrm{CO}_{2}$ equivalent). The GHG emissions values recorded during this period show that Romania is in line with the objective of reducing GHG emissions assumed.

- The share of RES energy in gross final consumption of energy in 2013 was $25.13 \%$, superior to that set for RES by the 2011 RES Directive. In order to achieve the national RES target, their promotion continued through green certificates. As of 31 December 2014, the power installed in the plants benefiting from the promotion system (excluding power installed in the groups that came out of the support scheme-hydro or wind with temporary expired accreditation) was about $3815 \mathrm{MW}$, out of which about 234 MW was deployed operation in January 2014-December 2014. It is estimated that between January and 15 March 2015, the installed power accredited for applying the green certificate promotion system was about $30 \mathrm{MW}$.

- Regarding energy efficiency, Romania has values below the national indicative targets. In 2012, the primary energy consumption reduction was $11616.6 \%$ (equivalent to $7.3 \mathrm{Mtoe}$ ) compared to the PRIMES forecast for 2007. To increase energy efficiency, the State aid scheme for the promotion of high efficiency cogeneration applies from April 2011. It provides for the granting of financial support to electricity and heat producers who commercially operate/operate high efficiency cogeneration plants with at least $10 \%$ fuel savings compared to separate production. Between January and December 2014, the support scheme benefited 37 economic operators. The financing of the measure is extra budgetary, with the costs borne by all consumers and energy-exporting suppliers. The total amount of bonus granted during the period January-December 2014 was 201.5 million euros.

\subsection{Organizational Change, KM Strategies, and OL and Readiness for Change}

Researchers were interested to find the factors that become the facilitators to change [74-76]. Lawrence and Lewin $[75,76]$ worked out on individual and group level dynamics that probably hamper or facilitate change initiatives at the workplace. Nalbone [77] used the phrase "readiness for change" for those factors that are facilitators of OC. Before 1990, many scholars attempted to explore different factors and contexts that prepare CR in organizations, i.e., employees' attitude, willingness to accept change, expected change benefits, and trust in management [78-80]. Armenkakis et al. [81] present a comprehensive definition of readiness for change construct as "beliefs, attitudes, and intentions regarding the extent to which changes are needed and the organization's capacity to successfully undertake those changes." Generally, employees resist change because they have to unlearn what they are doing and relearn what is required [82]. In this context, creating CR is not an easy task. Organizations can prepare CR at different levels [39,83]. Jones et al. [84] exhibits that during CR preparations, it is important to mould individuals' attitude. A high level of CR guarantees low resistance and increases the chances of successful implementation.

Knowledge is always being regarded as the core competency of an organization to grow and compete with their rivals [85,86]. Knowledge management $(\mathrm{KM})$ is all about managing knowledge for better organizational welfare [87]. KM works with its strategies, and personalization is regarded as face-to-face interaction and codification that is in document form [47]. These two strategies, personalization and codification, are based on two well-known knowledge types: tacit knowledge that is flourished through personalization strategy and explicit knowledge that is developed with the help of codification strategy. Extant literature is clearly indicates that KM has two broader strategies: personalization and codification $[46,48,88]$. The personalization strategy promotes socialization and states that knowledge can be effectively exchanged through physical interaction and face-to-face discussion; it can be one to one, one to many, and many to many $[47,89]$. Contrary to this, the codification 
strategy gives strength to documents, i.e., text, video, audio, and images. The codified knowledge requires a place like a central repository and can be accessed by anyone who has permission to use it $[47,48]$. Scholars are now trying to make an optimal mix of these two strategies by introducing a hybrid approach that has the positive aspects of these two strategies [46,90]. Andrews et al. [49] argued that with the help of KM mechanisms, employees and OL can be enhanced.

OL is categorized as single- and double-loop learning [29]. Context-specific knowledge is helpful for maintaining an optimal level of learning in organizations and is helpful for resolving major organizational issues, i.e., innovation, problem solving, and performance [24,59]. Likewise, personalization strategy is beneficial for change leaders to advance change by explaining the benefits of anticipated change to employees [90]. On the other hand, codification strategy provides manual and document material that is helpful to resolve the day-to-day problems of system-based change [84].

Change is the norm of every vital and live organization [14]. Weick and Quinn [91] presented a well-validated study on OC and explained its importance toward sustained performance.

Organizations have different types of change practices, i.e., process change, technology change, strategic change, and structural change [12,22]. In a change process, effectiveness in implementing change is more important [14]. Successful OC is the state where organizations are doing their routine business as they have done previously $[6,14,92]$. There are numerous factors that can probably affect the change process, i.e., organizational $\mathrm{CC}$, employees' perception about change, change agents' knowledge, and communication strategies $[84,93,94]$. Moreover, the dynamic orientation of the organization disturbs the change process; more dynamism leads to an increase in the difficulty in implementing change and vice versa [91].

Knowledge is of utmost importance for developing capabilities in change agents and plays an important role for the success of OC. KM strategies, personalization, and codification are the ways of delivering appropriate knowledge from change agents to employees and other stakeholders. $\mathrm{KM}$ strategies are helpful to communicate change information to intellectual capital from person to person, person to document, and document to person [47]. Bess et al. [28] explained the importance of OL toward transformational change. OL can be developed through personalization and codification strategies [95]. In this study, successful OC is measured on the basis of two dimensions: user satisfaction and system usage. These two dimensions are the core of every Enterprise Resource Planning (ERP) system as if users are satisfied from the current system then they ultimately implement this system without resistance and system usage ensures the frequency of usage [77]. The above-stated discussion provides clues to the following hypotheses:

H1. Personalization strategy positively influences OC.

H2. Codification strategy positively influences OC.

H3. Personalization strategy indirectly affects organizational change through OL.

H4. Codification strategy indirectly affects organizational change through OL.

H5. Personalization strategy indirectly affects organizational change through CR.

H6. Codification strategy indirectly affects organizational change through CR.

\subsection{Organizational Change Cynicism}

Organizational change cynicism (CC) can be defined as the extent to which expected and undergone change is resisted by stakeholders [16]. It is the outcome of the expected uncertain position caused by current change and flourishes a dislike state for anticipated change resulting from frustration, hopelessness and disillusionment in employees [18]. Due to globalization and stiff competition, change becomes necessary for organizations, and every change faces CC from all quarters $[16,96]$. Basically, CC is aroused because of discomfort resulting from the expected change $[16,20,96,97]$. Boomer et al. [98] suggested that CC has detrimental effects on prospective change. Recently, the cynicism concept has become very popular while discussing any change $[16,99,100]$. Bess et al. [28] suggested that effective OL is helpful to reduce the damaging effect of organizational CC through motivating employees and communicating the expected benefits of prospective change. Existing 
studies suggest that organizational CC can create weakening effects toward OC $[17,96,99,101,102]$. Likewise, Stanley et al. [19] explained that CC is one of the main resistors to OC and argued that organizations opt for CR mechanisms to deal with resistance and CC. Readiness for change creates change efficacy and valance that are helpful to manage resistance toward change [103]. This massive discussion concluded with the following hypothesis:

H7. Organizational CC negatively influences relationship between OL and successful OC.

H8. Organizational CC negatively influences relationship between readiness for change and successful OC (Figure 1).

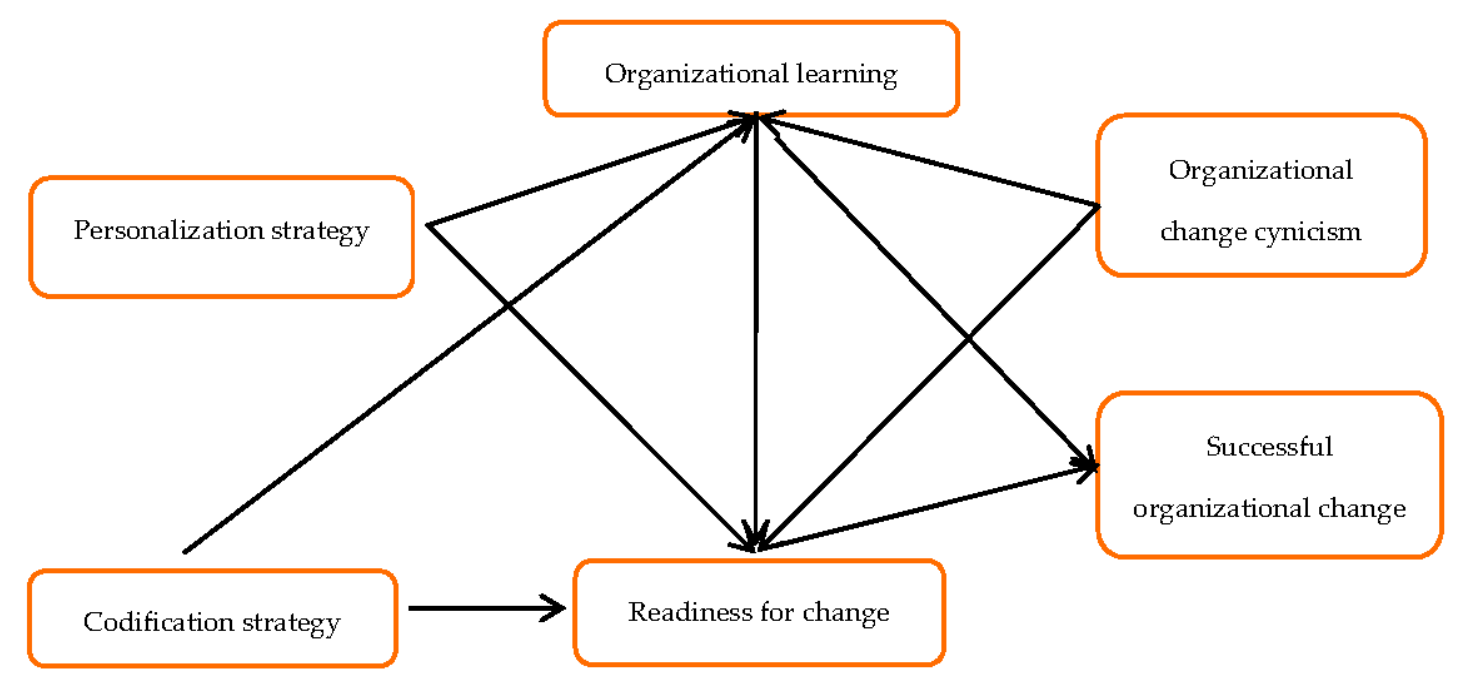

Figure 1. Research model.

\section{Research Model and Methodology}

\subsection{Research Methodology}

On the basis of the nature of this study, temporal research design is adopted as defined by [104] in which responses about KM strategies, OL, and CR are measured at stage 1 (T1) before implementing change and data regarding organizational CC and successful OC are measured at stage 2 (T2, 12 weeks after T1) after change implementation. The end users can better explain their satisfaction level about the new operating system at $\mathrm{T} 2$.

In this way, the temporal research design is helpful to minimize common variance by getting data at more than one point in time but cannot effectively address causality inference [105].

The ontological and epistemological assumptions of the current study suggested that there is a single reality that prevails about the exposition and knowledge can be defined and extracted from senses. Therefore, this study uses the positivistic research paradigm with a deductive reasoning approach. The hypotheses are drawn with the help of extant literature and tested afterward. Robson [106], presents that temporal study normally use positivistic research paradigm and explains the importance of literature in the formulation of hypotheses. In this study, we have followed the guidelines of [107] regarding hypotheses formulation from the contemporary literature of KM strategies, OL, CR, organizational CC, and OC.

\section{Measures and Instrument Development}

A questionnaire is used as the instrument of the current study and is formed on the basis of scales already developed by [108-110]. These scales are adapted using the Delphi approach through extensive discussion with academic and energy experts. Resultantly, some items have been dropped 
and some have been moulded to the context of the study. From the Daroch study, we preserved all three attributes of knowledge (knowledge acquisition, knowledge dissemination, and responsiveness to knowledge) but amended the items for each of the attributes. For instance, from 37 items related to knowledge acquisition, we eliminate KAF5 (Organizations works in partnership with international customers) because panel experts consider that this factor is not important for Romanian companies from energy sector. More, from 29 items related to knowledge dissemination, our expert eliminated KDF1 (Market dissemination is freely disseminated in our organization) because the organizational culture is often "closed to transparency" in these types of organization, and procedures related to knowledge dissemination are almost entirely opaque. Experts involved in the project believe that the energy sector is most "opaque" to disseminate information within and outside the organization from of all the sectors of the Romanian economy, with many common features from national security sector. From responsiveness to knowledge items, the panel expert eliminated KRF4 (Response to competition) because the national energy market has oligopolistic characteristics.

We adapt Holt et al. research to a five-point Likert scale instead of 7 in original research and eliminate from RC dimension- item "Personally beneficial" because in our type of organization, the hierarchical structure influence unfortunately rewards and promotions rather than results and fulfilment of objectives (individual performance).

We found very interesting research conducted by Jerez-Gomez et al. Our expert preserved most of the dimensions, but considering the features of companies involved in research, opted for the elimination of the dimension "Openness and experimentation."

To ensure validity of the instrument, pre-test and confirmatory factor analysis (CFA) using IBM SPSS AMOS 21 has been conducted and elaborated in detail in the data analysis portion. The scales of KM strategies, personalization and codification, have been adapted from scales developed by [81]. Scales of OL, CR, organizational CC, and successful OC are adapted from [28,111,112]. The two separate questionnaires are prepared at five-point Likert scale $(1=$ strongly disagree to $5=$ strongly agree). The first questionnaire includes items about KM strategies, OL, and readiness for change that is used at the pre-implementation stage. The second questionnaire contains items about CC and successful OC that is used at the post-implementation stage.

\subsection{Sampling Procedure and Features}

The data regarding end users have been obtained from the human resource departments of the respective companies. Guidelines and the precedence of the existing studies have been used to obtain a sample size of 380 end users from a given population frame. Initially, at T1, 380 questionnaires were distributed among end users of the stated companies, who were asked to incorporate their opinion about KM strategies, OL, and CR. Resultantly, 252 valid questionnaires were returned at $\mathrm{T} 1(66.31 \%)$.

After 12 weeks of implementing change (T2), these 252 end users were again requested to give their response on organizational CC and successful OC. Nalbone [77] have given direction that more than six weeks is appropriate to obtain a second response. At T1 and T2, 206 valid questionnaires were received and used for the final analysis.

\subsection{Results and Analysis}

The context of the current study is the energy sector of Romania. With respect to the demographic profile of the respondents, 185 men and 21 women responded to the questionnaires at both T1 and T2, having 89.8 and 10.2 percent, respectively. Mainly, the end users of the operating systems are the key respondents of this study. The current sample includes five respondents with one to five years of experience, 139 with six to ten years, 54 with 11-15 years, and eight with $16-20$ years. The experience of the respondents suggests that maximum respondents lie between five and 15 years of experience that is negative as more experience generates more resistance toward OC. Their age profile lies between 30 and 40 years. 


\subsubsection{Reliability and Descriptive Statistics}

Initially, reliability analysis is executed to check the appropriateness of data. Reliability analysis measures the internal consistency of the data. Cronbach's $\alpha$ values of the current study are in the range from 0.65 to 0.89 that is appropriate for further analysis. Moreover, descriptive statistic, mean, and standard deviation have explained the general trend in the data and values reflect a positive trend prevailed in the data except organizational CC. Moreover, the values of correlation coefficient describe the strength of relationship among variables. There is moderate strength of relationship among variables as the values of correlation coefficient are above 0.30 and below 0.75 (Table 1).

Table 1. Reliability and descriptive analytics.

\begin{tabular}{cccccccccc}
\hline Constructs & $\boldsymbol{\alpha}$ & Mean & SD & $\mathbf{1}$ & $\mathbf{2}$ & $\mathbf{3}$ & $\mathbf{4}$ & $\mathbf{5}$ & $\mathbf{6}$ \\
\hline Personalization strategy & 0.698 & 3.33 & 1.07 & - & & & & & \\
Codification strategy & 0.682 & 3.32 & 1.05 & 0.41 & & & & & \\
OL & 0.793 & 3.18 & 1.03 & 0.63 & 0.51 & & & & \\
CR & 0.848 & 3.05 & 1.11 & 0.58 & 0.56 & 0.73 & & & \\
Organizational CC & 0.787 & 2.61 & 0.87 & -0.31 & -0.39 & -0.47 & -0.31 & & \\
Change implementation & 0.868 & 3.09 & 0.95 & 0.52 & 0.57 & 0.55 & 0.71 & -0.37 & - \\
\hline
\end{tabular}

\subsubsection{Validity Analysis}

To measure the validity of the proposed model and instrument, CFA was executed. The current study contains six latent variables that are forming a successful OC model. At the final stage, triggers provided a healthy model fit of the current study $(\mathrm{CMIN} / \mathrm{df}=2.76<3, \mathrm{CFI}=0.975>0.90$, $\mathrm{TLI}=0.963>0.90$, RMSEA $=0.051<0.08, \mathrm{GFI}=0.952>0.90, \mathrm{AGFI}=0.921>0.90)($ Table 2$)$.

Table 2. Validity check through confirmatory factor analysis.

\begin{tabular}{ccccccc}
\hline Description & CMIN/df & AGFI & GFI & RMSEA & CFI & TLI \\
\hline Preliminary indices & 7.77 & 0.839 & 0.879 & 0.087 & 0.872 & 0.899 \\
Model fit value indices & 2.76 & 0.921 & 0.952 & 0.051 & 0.975 & 0.963 \\
\hline
\end{tabular}

Note: The thresholds observed for model fit are as CMIN/df $<0.3$, AGFI-GFI-CFI-TLIW $>0.90$, RMSEA $<0.080$.

\section{Results}

\subsection{Hypothesis Testing}

To test the direct effect of KM strategies on successful OC, multiple regression analysis was conducted. The results showed 46 percent variation found in success of OC due to KM strategies $(f$-value $=98.29, p<0.001)$. The in-depth analysis reflects that personalization strategy is highly valuable to implement change successfully as compared to codification strategy (personalization $(\beta=0.57, t=10.21, p<0.001)$, codification $(\beta=0.19, t=2.98, p<0.005))$ (Table 3$)$.

Table 3. Direct effect through multiple regression analysis.

\begin{tabular}{ccccccc}
\hline Relationship & $\boldsymbol{R}^{\mathbf{2}}$ & Adj. $\boldsymbol{R}^{\mathbf{2}}$ & $\boldsymbol{f}$-Value & $\boldsymbol{\beta}$ & $\boldsymbol{t}$-Value & $\boldsymbol{p}$ \\
\hline Overall & 0.43 & 0.41 & 98.29 & & & $* * *$ \\
PS $\rightarrow$ SOC & & & & 0.57 & 10.21 & $* * *$ \\
CS $\rightarrow$ SOC & & & & 0.19 & 2.98 & 0.005 \\
\hline
\end{tabular}

Notes: PS-personalization strategy; CS-codification strategy; SOC-successful organizational change. *** $p<0.001$. 


\section{Mediation Analysis}

Mediation analysis was conducted to measure the indirect effect of personalization strategy on OC through OL and CR. In the first mediation model, OL is taken as a mediator between KM strategies and successful OC. The results of A-Path confirm that there is a positive relationship between personalization strategy and OL $(\beta=0.648, p<0.001)$. Further, B-Path reveals a positive relationship between OL and OC with $(\beta=0.257, p<0.001)$. Similarly, C-Path assured a positive impact of personalization strategy on $O C(\beta=0.540, p<0.001)$, and $C^{\prime}$-Path also confirms the mediation effect of OL $(\beta=0.412, p<0.001)$. A comparison of $C-C^{\prime}$ paths has shown that there is a partial correlation that exists. The overall model is significant with an $R^{2}$ value of 48.8 percent and an Analysis of variance (ANOVA) value of 107.63. In the second phase, indirect effect of codification strategy is tested on OC through OL. The results of A-Path confirm that there is positive relationship between codification strategy and OL $(\beta=0.357, p<0.001)$. Further, B-Path reveals a positive relationship between OL and OC with $(\beta=0.257, p<0.001)$. Similarly, C-Path assured a positive impact of codification strategy on OC $(\beta=0.339, p<0.001)$ and $C^{\prime}$-Path also confirms the mediation effect of OL $(\beta=0.185, p<0.001)$. A comparison of $C-C^{\prime}$ paths has shown that there is a partial correlation that exists. The overall model is significant with an $R^{2}$ value of 44.9 percent and an ANOVA value of 71.89 (Table 4).

Table 4. Indirect effect of knowledge management (KM) strategies on SOC through OL and RFC.

\begin{tabular}{ccccccccc}
\hline Relationships & $\boldsymbol{R}^{\mathbf{2}}$ & Adj. $\boldsymbol{R}^{\mathbf{2}}$ & $\boldsymbol{f}$-Value & Path-A & Path-B & Path-C & Path-C & $\boldsymbol{p}$ \\
\hline $\mathrm{PS} \rightarrow$ OL $\rightarrow$ SOC & 0.488 & 0.486 & 107.63 & 0.648 & 0.257 & 0.540 & 0.412 & $* * *$ \\
$\mathrm{CS} \rightarrow$ OL $\rightarrow$ SOC & 0.449 & 0.447 & 71.89 & 0.357 & 0.257 & 0.339 & 0.185 & 0.001 \\
$\mathrm{PS} \rightarrow$ RFC $\rightarrow$ SOC & 0.429 & 0.414 & 97.61 & 0.609 & 0.231 & 0.512 & 0.391 & $* * *$ \\
$\mathrm{CS} \rightarrow$ RFC $\rightarrow$ SOC & 0.415 & 0.389 & 58.63 & 0.321 & 0.231 & 0.328 & 0.169 & 0.003 \\
\hline
\end{tabular}

Notes: PS-personalization strategy; CS—codification strategy; OL-organizational learning; SOC—successful organizational change; RFC-readiness for change; IV-independent variable; DV-dependent variable; $M V-$ mediating variable. Path-A $=I V \rightarrow M V$, Path-B $=M V \rightarrow D V$, Path-C $=I V \rightarrow D V$, Path- $C^{\prime}=I V \rightarrow M V \rightarrow D V$. *** $p<0.001$.

In the second mediation model, $\mathrm{CR}$ is taken as a mediator between $\mathrm{KM}$ strategies and successful OC. The results of A-Path confirm that there is a positive relationship between personalization strategy and CR $(\beta=0.609, p<0.001)$. Further, B-Path reveals a positive relationship between CR and OC with $(\beta=0.231, p<0.001)$. Similarly, $C$-Path assured a positive impact of personalization strategy on OC $(\beta=0.512, p<0.001)$ and $C^{\prime}$-Path also confirms the mediation effect of $C R(\beta=0.391, p<0.001)$. A comparison of $C-C^{\prime}$ paths has shown that there is a partial correlation that exists. The overall model is significant with an $R^{2}$ value of 42.9 percent and an ANOVA value of 97.61.

In the second phase, the indirect effect of codification strategy is tested on OC through CR. The results of A-Path confirm that there is a positive relationship between codification strategy and $C R$ $(\beta=0.321, p<0.001)$.

Further, B-Path reveals a positive relationship between OL and OC with $(\beta=0.231, p<0.001)$. Similarly, C-Path assured a positive impact of codification strategy on OC $(\beta=0.328, p<0.001)$, and $C^{\prime}$-Path also confirms the mediation effect of OL $(\beta=0.169, p<0.001)$. A comparison of C-C' paths has shown that partial correlation exists. The overall model is significant with an $R^{2}$ value of 41.5 percent and an ANOVA value of 58.63 (Figure 2). In order to control for the effect of multiple testing, we use the FDR method developed by Benjamini and Hochberg [113] for finite sample proofs, and the results were appropriate. 


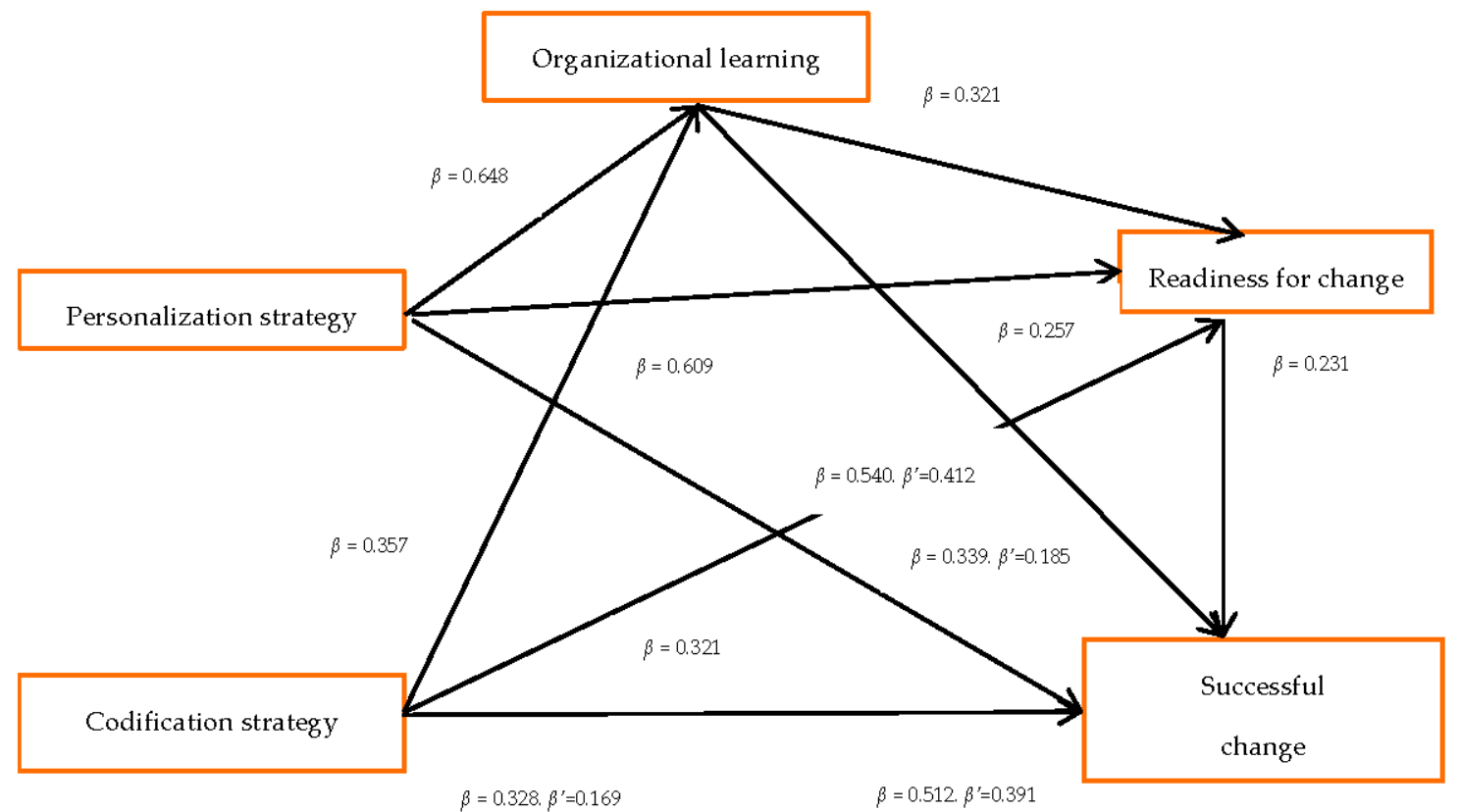

Figure 2. Mediation model.

\subsection{Moderation Analysis}

The interactive effect of organizational CC in the relationship among OL, readiness for change, and successful OC is measured using a multiple moderated regression analysis test with interaction term (Table 5).

Table 5. Interactive effect of CC in between OL-RFC and SOC.

\begin{tabular}{|c|c|c|c|c|c|c|c|}
\hline Relationships & $R^{2}$ & $\operatorname{Adj} . R^{2}$ & $f$-Value & B & SEE & $t$-Value & Sig. \\
\hline $\mathrm{OL}-\mathrm{CC} \rightarrow \mathrm{SOC}$ & 0.449 & 0.445 & 71.92 & & & & $* * *$ \\
\hline $\mathrm{OL} \rightarrow \mathrm{SOC}$ & & & & 0.51 & 0.04 & 8.89 & $* * *$ \\
\hline $\mathrm{CC} \rightarrow \mathrm{SOC}$ & & & & -0.15 & 0.05 & -2.79 & $* * *$ \\
\hline $\mathrm{OL}-\mathrm{CC}-\mathrm{OL}^{*} \mathrm{CC} \rightarrow \mathrm{SOC}$ & 0.426 & 0.419 & 48.48 & & & & $* * *$ \\
\hline $\mathrm{OL}^{*} \mathrm{CC} \rightarrow \mathrm{SOC}$ & & & & 0.29 & 0.03 & 2.39 & 0.003 \\
\hline $\mathrm{RFC}-\mathrm{CC} \rightarrow \mathrm{SOC}$ & 0.435 & 0.421 & 69.54 & & & & $* * *$ \\
\hline $\mathrm{RFC} \rightarrow \mathrm{SOC}$ & & & & 0.49 & 0.05 & 8.99 & $* * *$ \\
\hline $\mathrm{CC} \rightarrow \mathrm{SOC}$ & & & & -0.19 & 0.05 & -2.78 & $* * *$ \\
\hline $\mathrm{RFC}-\mathrm{CC}-\mathrm{RFC}^{*} \mathrm{CC} \rightarrow \mathrm{SOC}$ & 0.392 & 0.372 & 45.94 & & & & $* * *$ \\
\hline $\mathrm{RFC}^{*} \mathrm{CC} \rightarrow \mathrm{SOC}$ & & & & 0.29 & 0.03 & 2.31 & 0.004 \\
\hline
\end{tabular}

Notes: OL-organizational learning; CC—change cynicism; SOC-successful organizational change; RFC—readiness for change; SEE—standard error of estimate. ${ }^{* * *} p<0.001$.

The results revealed that organizational CC weakens the relationship between OL and successful OC $\left(\Delta R^{2}=1.99\right.$ percent, $f$-value $\left.=48.48, p<0.001\right)$. The OL preforms a buffering effect to mitigate the detrimental effects of organizational CC on successful OC. Similarly, CC has also reduced the positive effects of readiness for change toward successful OC $\left(\Delta R^{2}=4.3\right.$ percent, $f$-value $\left.=45.94, p<0.001\right)$ (Figure 3). 


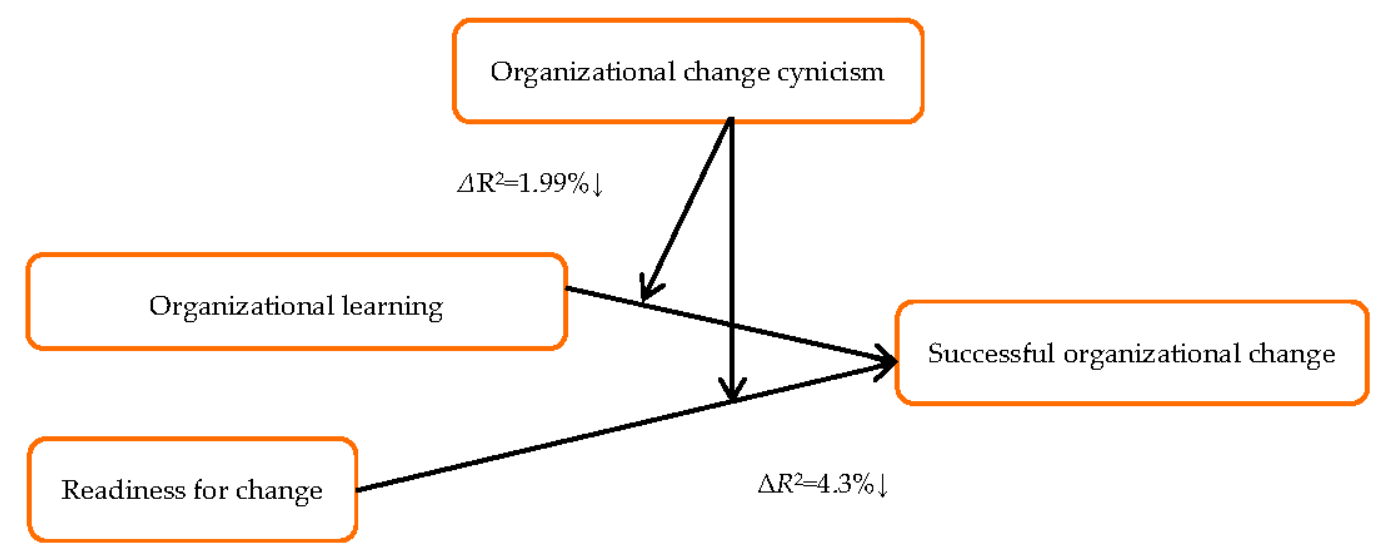

Figure 3. Moderation model.

\section{Discussion}

Although previous literature gives evidence that KM strategies have a direct effect on different organizational outcomes [45], little work has yet been done regarding KM strategies in the relationship with OL and OC. In the current study, we empirically investigate the OC model through KM strategies, $\mathrm{OL}$, and change. In addition, this study also contains information on how OL and readiness for change is helpful to reduce the injurious effects of CC on successful OC.

At first, findings of direct effect indicated that KM strategies have a positive impact on successful OC. These findings are consistent as hypothesized and somewhat with previous research [45] that invariably stipulate that there is a link between KM strategies and OC. Second, results of the mediation test confirm that KM strategies have an indirect effect on OC through OL and CR. This is the novelty of this research, as this relation has not yet been explored. The results specify that OL and CR have been partially mediating the KM strategies-OC relationship. Lastly, researchers used an interaction term by applying a moderation test to unveil the interactive effect of organizational CC in the relationship between OL and CR successful change implementation. Results have suggested that CC can weaken the relationship among OL, readiness for change, and OC. The stated results are consistent with previous studies regarding organizational CC [17]. The results also indicate that if an extensive learning environment has prevailed in organizations, this element can reduce the harmful effects of CC on OC.

\section{Conclusions}

Change becomes the norm for vital and growing organizations. Organizations are continuously adopting numerous methods to initiate change for the betterment of organizational outcomes, i.e., changes in processes, technology, culture, infrastructure, intellectual capability, and management. The energy sector of Romania is currently forming a new shape by providing extensive services to its customers that are market driven and are aligned with international norms. Many companies are going to change their ERP system for the facilitation of their valued clients. Meanwhile, organizations are facing the organizational CC that causes the failure of the overall change process.

The results of the current study concluded that success in OC can be enhanced by adopting KM strategies, personalization, and codification. Through these strategies, the optimal level of OL can be grasped that will ultimately be helpful to reduce the CC. This study explored a new vision to implement these types of OC successfully and obtain their early benefits by using personalization and codification $\mathrm{KM}$ strategies and uncover the mediating effect of OL and readiness for change. KM strategies have a positive and direct impact on successful change implementation, and these strategies are helpful for readiness to change as well. These are equally beneficial for reducing employee cynicism regarding OC, which will ultimately increase the chances of successful change implementation. These empirical findings expose the importance of KM strategies that are needed at the pre-implementation phase. 
These strategies are able to form strong foundations for readiness for change and OL. KM strategies are proved as the key predictors for developing readiness for change and are also helpful to reduce CC. Overall, the results highlighted that energy companies can implement an ERP-based change effectively through KM strategies. The results are equally valuable for all Romanian organizations that are currently changing their working environment.

\subsection{Theoretical and Practical Implications}

The current study contributes to the existing theory with an innovative model of successful OC with the help of KM strategies, OL, and CR mechanisms, as contemporary literature is silent with respect to the KM and OC relationship. Theoretical grounds of KM suggest that OL is one of its outcomes [26] and leads to develop readiness for change in organizations [114,115].

This study adds to the existing literature and opens up new avenues for further research in the area of OC using KM concepts. Further, the significance of mediation effect enlarges the use of OL and $\mathrm{CR}$ in the energy sector change process.

With respect to practical orientation, this study is beneficial for the stated energy companies to emphasize the personalization strategy to increase the success elements of implementing OC, as the personalization KM strategy performs better to develop OL and CR. The personalization strategy boosts socialization among management, change agents, and employees, which leads to developing change commitment and efficacy. Using the codification strategy, change agents can resolve the post-implementation issues of employees about change. Leaning orientation is helpful to alter the thinking patterns of employees about change appropriateness and enhance their trust level on current management. The empirical investigation answers one of the practitioners' complaints about change process, which is, "no one tells us how to do it." Results give an insight to the practitioner to opt for an optimal mix of codification and personalization strategies for better change outcomes as these strategies affect other organizational outcomes that might be considered as the facilitator of a change process, i.e., employee knowledge, OL, motivation, future vision, etc.

Moreover, researchers that are interested in $\mathrm{OC}$ and $\mathrm{KM}$ can find a unique productive avenue in this study as well. It is also observed that $\mathrm{CR}$ is a better predictor to advance change as compared to OL. Ironically, OL also becomes a facet of CR. So, it is important for change agents to utilize KM strategies to enhance readiness for change for better change implementation. At this stage, the role of agents is to develop change efficacy, change appropriateness, and management support for better development of CR. In this respect, we should mention the importance of expanding our research by using concepts from cognitive psychology (i.e., declarative and non-declarative knowledge) and the relationship with OL [116]. This study suggests that management has to promote the personalization strategy at both times-pre- and post-implementation - to effectively grasp the benefits of CR to advance system-based change in organizations. On the other hand, the meditation results of OL between KM strategies and OC implementation also highlight the importance of formal and on-the-job training in preparing employee motivation and knowledge strength about operating system-related change. Additionally, codification strategy is equally beneficial after the change implementation phase in order for end users to obtain help with routine tasks and problems, i.e., manuals about system procedures to perform a particular job or task.

\subsection{Limitations and Future Directions of Research}

Despite the various findings and implications, the current study contains limitations as well. First, there was a low response rate from a limited geographical area restricted by its generalizability to other sectors and countries. In future, it is recommended the geographical strength of the study be enlarged and all means be utilized to increase the response rate to an optimal level [117]. Moreover, the respondents that express their views and T1 and cannot respond to T2 may change the results of this study. For future studies, it is suggested that the time span be increased as per context of the study in consultation with experts of the concerned area. 
Author Contributions: All authors share equal contribution to this paper. All authors wrote the paper and revised the manuscript for intellectual content and read and approved the final manuscript.

Conflicts of Interest: The authors declare no conflict of interest.

\section{References}

1. Ceptureanu, S.I.; Ceptureanu, E.G.; Marin, I. Assessing role of strategic choice on organizational performance by Jacquemin- Berry entropy index. Entropy 2017, 19, 448. [CrossRef]

2. Armeanu, D.S.; Vintila, G.; Gherghina, S.C. Does Renewable Energy Drive Sustainable Economic Growht? Multivariate Panel Data Evidence from EU-28 Countries. Energies 2017, 10, 381. [CrossRef]

3. Balogun, J.; Hailey, V. Exploring Strategic Change, 2nd ed.; Prentice Hall: London, UK, 2004.

4. Burnes, B. Managing Change: A Strategic Approach to Organisational Dynamics, 4th ed.; Prentice Hall: Harlow, UK, 2004.

5. Decker, P.; Durand, R.; Mayfield, C.O.; McCormack, C.; Skinner, D.; Perdue, G. Predicting implementation failure in organization change. J. Organ. Cult. Commun. Confl. 2012, 16, $29-49$.

6. Jacobs, G.; van Witteloostuijn, A.; Christe-Zeyse, J. A theoretical framework of organizational change. J. Organ. Chang. Manag. 2013, 26, 772-792. [CrossRef]

7. Llamas-Sanchez, R.; Garcia-Morales, V.; Martin-Tapia, I. Factors affecting institutional change: A study of the adoption of local agenda 21 in Spain. J. Organ. Chang. Manag. 2013, 26, 1045-1070. [CrossRef]

8. Rees, C.J.; Hassard, J. Perspectives on organizational change in Asia. J. Organ. Chang. Manag. 2010, 23, 480-484. [CrossRef]

9. Elrod, P.D.; Tippett, D.D. The 'death valley' of change. J. Organ. Chang. Manag. 2002, 15, 273-291. [CrossRef]

10. Ceptureanu, E.G.; Ceptureanu, S.I.; Luchian, C.E.; Luchian, I. Quality management in project management consulting. A case study in an international consulting company. Amfiteatru Econ. 2017, 19, 215-230.

11. Batra, S. Do new ventures benefit from strategic change or persistence? A behavioral perspective. J. Organ. Chang. Manag. 2016, 29, 310-319. [CrossRef]

12. Wu, Y.; Xi, Y.; Liang, Q.; Groleau, C.; Demers, C.; Engestrom, Y.; Wei, Z. Top management team diversity and strategic change: The moderating effects of pay imparity and organization slack. J. Organ. Chang. Manag. 2011, 24, 267-281. [CrossRef]

13. Millar, C.; Hind, P.; Magala, S. Sustainability and the need for change: Organizational change and transformational vision. J. Organ. Chang. Manag. 2012, 25, 489-500. [CrossRef]

14. Armenakis, A.A.; Bedeian, A.G. Organizational change: A review of theory and research in the 1990s. J. Manag. 1999, 25, 293-315. [CrossRef]

15. Bruque, S.; Moyano, J.; Eisenberg, J. Individual adaptation to IT-induced change: The role of social networks. J. Manag. Inf. Syst. 2008, 25, 177-206. [CrossRef]

16. Brown, M.; Cregan, C. Organizational change cynicism: The role of employee involvement. Hum. Resour. Manag. 2008, 47, 667-686. [CrossRef]

17. Barton, L.C.; Ambrosini, V. The moderating effect of organizational change cynicism on middle manager strategy commitment. Int. J. Hum. Resour. Manag. 2013, 24, 721-746. [CrossRef]

18. Andersson, L.M. Employee cynicism: An examination using a contract violation framework. Hum. Relat. 1996, 49, 1395-1418. [CrossRef]

19. Stanley, D.J.; Meyer, J.P.; Topolnytsky, L. Employee cynicism and resistance to organizational change. J. Bus. Psychol. 2005, 19, 429-459. [CrossRef]

20. Chiaburu, D.S.; Peng, A.C.; Oh, I.-S.; Banks, G.C.; Lomeli, L.C. Antecedents and consequences of employee organizational cynicism: A meta-analysis. J. Vocat. Behav. 2013, 83, 181-197. [CrossRef]

21. Bierly, P.E., III; Kessler, E.H.; Christensen, E.W. Organizational learning, knowledge and wisdom. J. Organ. Chang. Manag. 2000, 13, 595-618. [CrossRef]

22. Sune, A.; Gibb, J. Dynamic capabilities as patterns of organizational change: An empirical study on transforming a firm's resource base. J. Organ. Chang. Manag. 2015, 28, 213-231. [CrossRef]

23. Attewell, P. Technology diffusion and organizational learning: The case of business computing. Organ. Sci. 1992, 3, 1-19. [CrossRef]

24. Brandi, U.; Iannone, R.L. Innovative organizational learning technologies: Organizational learning's Rosetta stone. Dev. Learn. Organ. 2015, 29, 3-5. [CrossRef] 
25. Cho, V. A study of the impact of organizational learning on information system effectiveness. Int. J. Bus. Inf. 2015, 2. [CrossRef]

26. Imran, M.K.; Ilyas, M.; Aslam, U.; Rahman, U. Organizational learning through transformational leadership. Learn. Organ. 2016, 23, 232-248. [CrossRef]

27. López, S.; Manuel Montes Peón, J.; José Vázquez Ordás, C. Managing knowledge: The link between culture and organizational learning. J. Knowl. Manag. 2004, 8, 93-104. [CrossRef]

28. Bess, K.D.; Perkins, D.D.; McCown, D.L. Testing a measure of organizational learning capacity and readiness for transformational change in human services. J. Prev. Interv. Commun. 2010, 39, 35-49. [CrossRef] [PubMed]

29. Crossan, M.M.; Lane, H.W.; White, R.E. An organizational learning framework: From intuition to institution. Acad. Manag. Rev. 1999, 24, 522-537.

30. Purushothaman, A. Organizational learning: A road map to evaluate learning outcomes in knowledge intensive firms. Dev. Learn. Organ. Int. J. 2015, 29, 11-14. [CrossRef]

31. Bartolacci, F.; Castellano, N.; Nicola, G.; Cerqueti, R. The impact of innovation on companies' performance: An entropy-based analysis of the STAR market segment of the Italian Stock Exchange. Technol. Anal. Strateg. Manag. 2015, 27, 102-123. [CrossRef]

32. Eby, L.T.; Adams, D.M.; Russell, J.E.; Gaby, S.H. Perceptions of organizational readiness for change: Factors related to employees' reactions to the implementation of team based selling. Hum. Relat. 2000, 53, 419-442. [CrossRef]

33. Lehman, W.E.; Greener, J.M.; Simpson, D.D. Assessing organizational readiness for change. J. Subst. Abuse Treat. 2002, 22, 197-209. [CrossRef]

34. Rusly, F.H.; Sun, P.Y.-T.; Corner, J.L. Change readiness: Creating understanding and capability for the knowledge acquisition process. J. Knowl. Manag. 2015, 19, 1204-1223. [CrossRef]

35. Ceptureanu, E.G.; Ceptureanu, S.I.; Popescu, I.D. Relationship between Entropy, Corporate Entrepreneurship and Organizational Capabilities in Romanian Medium Sized Enterprises. Entropy 2017, 19, 412. [CrossRef]

36. Choi, M.; Ruona, W.E. Individual readiness for organizational change and its implications for human resource and organization development. Hum. Resour. Dev. Rev. 2011, 10, 46-73. [CrossRef]

37. Neves, P. Readiness for change: Contributions for employee's level of individual change and turnover intentions. J. Chang. Manag. 2009, 9, 215-231. [CrossRef]

38. Holt, D.T.; Vardaman, J.M. Toward a comprehensive understanding of readiness for change: The case for an expanded conceptualization. J. Chang. Manag. 2013, 13, 9-18. [CrossRef]

39. Norcross, J.C.; Krebs, P.M.; Prochaska, J.O. Stages of change. J. Clin. Psychol. 2011, 67, 143-154. [CrossRef] [PubMed]

40. Rusly, F.; Yih-Tong Sun, P.; Corner, J.L. The impact of change readiness on the knowledge sharing process for professional service firms. J. Knowl. Manag. 2014, 18, 687-709. [CrossRef]

41. Gurjeet, D.; Ausloos, M. Modelling and measuring the irrational behaviour of agents in financial markets: Discovering the psychological soliton. Chaos Solitons Fractals 2016, 88, 119-125.

42. Self, D.R.; Schraeder, M. Enhancing the success of organizational change: Matching readiness strategies with sources of resistance. Leadersh. Organ. Dev. J. 2009, 30, 167-182. [CrossRef]

43. Brandi, U.; Elkjaer, B. Organizational learning viewed from a social learning perspective. In Handbook of Organizational Learning and Knowledge Management, 2nd ed.; Easterby-Smith, M., Lyles, M.A., Eds.; Wiley: Chichester, UK, 2011; pp. 33-42.

44. Ceptureanu, S.I.; Ceptureanu, E.G.; Orzan, M.C.; Marin, I. Toward a Romanian NPOs Sustainability Model: Determinants of sustainability. Sustainability 2017, 9, 966. [CrossRef]

45. Maier, R.; Remus, U. Implementing process-oriented knowledge management strategies. J. Knowl. Manag. 2003, 7, 62-74. [CrossRef]

46. Earl, M. Knowledge management strategies: Toward a taxonomy. J. Manag. Inf. Syst. 2001, 18, $215-233$.

47. Hansen, M.T.; Nohria, N.; Tierney, T. What's your strategy for managing knowledge? Harv. Bus. Rev. 1999, 77, 106-116. [PubMed]

48. Scheepers, R.; Venkitachalam, K.; Gibbs, M.R. Knowledge strategy in organizations: Refining the model of Hansen, Nohria and Tierney. J. Strateg. Inf. Syst. 2004, 13, 201-222. [CrossRef]

49. Andrews, K.M.; Delahaye, B.L. Influences on knowledge processes in organizational learning: The psychosocial filter. J. Manag. Stud. 2000, 37, 797-810. [CrossRef] 
50. Pan, S.L.; Scarbrough, H. Knowledge management in practice: An exploratory case study. Technol. Anal. Strateg. Manag. 1999, 11, 359-374. [CrossRef]

51. Cangelosi, V.E.; Dill, W.R. Organizational learning: Observations toward a theory. Adm. Sci. Q. 1965, 10, 175-203. [CrossRef]

52. Shrivastava, P. A typology of organizational learning systems. J. Manag. Stud. 1983, 20, 7-28. [CrossRef]

53. Chi, M.T.; Roy, M.; Hausmann, R.G. Observing tutorial dialogues collaboratively: Insights about human tutoring effectiveness from vicarious learning. Cognit. Sci. 2008, 32, 301-341. [CrossRef] [PubMed]

54. Rotundo, G.; Ausloos, M. Complex-valued information entropy measure for networks with directed links (digraphs). Application to citations by community agents with opposite opinions. Eur. Phys. J. B 2013, 86, 169. [CrossRef]

55. Adams, M.E.; Day, G.S.; Dougherty, D. Enhancing new product development performance: An organizational learning perspective. J. Prod. Innov. Manag. 1998, 15, 403-422. [CrossRef]

56. Goh, S.C.; Elliott, C.; Quon, T.K. The relationship between learning capability and organizational performance: A meta-analytic examination. Learn. Organ. 2012, 19, 92-108. [CrossRef]

57. Bass, B.M.; Avolio, B.J.; Jung, D.I.; Berson, Y. Predicting unit performance by assessing transformational and transactional leadership. J. Appl. Psychol. 2003, 88, 207-218. [CrossRef] [PubMed]

58. March, J.G. Footnotes to organizational change. Adm. Sci. Q. 1981, 26, 563-577. [CrossRef]

59. Chien, S.-Y.; Tsai, C.-H. Dynamic capability, knowledge, learning, and firm performance. J. Organ. Chang. Manag. 2012, 25, 434-444. [CrossRef]

60. Wang, C.L.; Ahmed, P.K. Organisational learning: A critical review. Learn. Organ. 2003, 10, 8-17. [CrossRef]

61. López, S.; Manuel Montes Peón, J.; José Vazquez Ordás, C. Organizational learning as a determining factor in business performance. Learn. Organ. 2005, 12, 227-245. [CrossRef]

62. Zagoršek, H.; Dimovski, V.; Škerlavaj, M. Transactional and transformational leadership impacts on organizational learning. J. East Eur. Manag. Stud. 2009, 14, 144-165.

63. Kern, F.; Howlett, M. Implementing transition management as policy reforms: A case study of the Dutch energy sector. Policy Sci. 2009, 42, 391. [CrossRef]

64. Zhang, Z.X. Why did the energy intensity fall in China's industrial sector in the 1990s? The relative importance of structural change and intensity change. Energy Econ. 2003, 25, 625-638. [CrossRef]

65. Strengers, Y. Peak electricity demand and social practice theories: Reframing the role of change agents in the energy sector. Energy Policy 2012, 44, 226-234. [CrossRef]

66. Sagara, A.D.; der Zwaanab, B. Technological innovation in the energy sector: R\&D, deployment, and learning-by-doing. Energy Policy 2006, 34, 2601-2608.

67. Nilsson, M. Learning and Frames, and Environmental Policy Integration: The Case of Swedish Energy Policy. Environ. Plan. C Politics Space 2005, 23, 207-226. [CrossRef]

68. Kobosa, P.H.; Erickson, J.D.; Drennen, T.E. Technological learning and renewable energy costs: Implications for US renewable energy policy. Energy Policy 2006, 34, 1645-1658. [CrossRef]

69. Edwards, J.S. Knowledge management in the energy sector: Review and future directions. Int. J. Energy Sect. Manag. 2008, 2, 197-217. [CrossRef]

70. Maimone, F.; Sinclair, M. Dancing in the dark: Creativity, knowledge creation and (emergent) organizational change. J. Organ. Chang. Manag. 2014, 27, 344-361. [CrossRef]

71. Romanian Ministry of Energy- "Analysis of Current State" and "Romania's International Commitments in the Energy Sector". Available online: http:/ / energie.gov.ro/wp-content/uploads/2016/02/ActualizareAnaliza-sistem_feb-2016.pdf (accessed on 17 May 2017).

72. Romanian Ministry of Economy_ “Romania's Energy Strategy for the Period 2007-2020 Updated for the Period 2011-2020". Available online: http:/ /www.minind.ro/energie/STRATEGIA_energetica_actualizata. pdf (accessed on 2 June 2017).

73. Romanian Ministry of Energy-“Energy Strategy of Romania 2016-2030, with the Prospect of 2050”. Available online: http:/ / www.solarthermalworld.org/sites/gstec/files/news/file/2016-12-30/energy_ strategy_2016-2030_full_version_in_romanian.pdf (accessed on 25 June 2017).

74. Coch, L.; French, J.R. Overcoming resistance to change. Hum. Relat. 1948, 1, 512-532. [CrossRef]

75. Lawrence, P.R. How to deal with resistance to change. Harv. Bus. Rev. 1954, 32, 49-57. [CrossRef]

76. Lewin, K. Field Theory in Social Sci; Harper: New York, NY, USA, 1951.

77. Nalbone, P.J. Improving readiness for change and innovation: A case study. J. Instr. Dev. 1979, 3, 2-9. [CrossRef] 
78. Amburgey, T.L.; Kelly, D.; Barnett, W.P. Resetting the clock: The dynamics of organizational change and failure. Acad. Manag. Proc. 1990, 1990, 160-164. [CrossRef]

79. Rashford, N.S.; Coghlan, D. Phases and levels of organisational change. J. Manag. Psychol. 1989, 4, 17-22. [CrossRef]

80. Ven de Ven, A.H.; Huber, G.P. Longitudinal field research methods for studying processes of organizational change. Organ. Sci. 1990, 1, 213-219.

81. Armenakis, A.A.; Harris, S.G.; Mossholder, K.W. Creating readiness for organizational change. Hum. Relat. 1993, 46, 681-703. [CrossRef]

82. Caldwell, D.F.; Chatman, J.; O'Reilly, C.A., III; Ormiston, M.; Lapiz, M. Implementing strategic change in a health care system: The importance of leadership and change readiness. Health Care Manag. Rev. 2008, 33, 124-133. [CrossRef] [PubMed]

83. Rafferty, A.E.; Jimmieson, N.L.; Armenakis, A.A. Change readiness a multilevel review. J. Manag. 2013, 39, 110-135.

84. Jones, R.A.; Jimmieson, N.L.; Griffiths, A. The impact of organizational culture and reshaping capabilities on change implementation success: The mediating role of readiness for change. J. Manag. Stud. 2005, 42, 361-386. [CrossRef]

85. Appleyard, M.M. How does knowledge flow? Interfirm patterns in the semiconductor industry. Strateg. Manag. J. 1996, 17, 137-154. [CrossRef]

86. Nonaka, I.; Byosiere, P.; Borucki, C.C.; Konno, N. Organizational knowledge creation theory: A first comprehensive test. Int. Bus. Rev. 1994, 3, 337-351. [CrossRef]

87. Alavi, M.; Leidner, D.E. Knowledge management systems: Issues, challenges, and benefits. Commun. Assoc. Inf. Syst. 1999, 1, 1-27.

88. Kumar, J.; Ganesh, L. Balancing knowledge strategy: Codification and personalization during product development. J. Knowl. Manag. 2011, 15, 118-135. [CrossRef]

89. Davenport, T.H.; Guest, V.G. Special issue: Knowledge management. J. Manag. Inf. Syst. 2001, 18, 3-4. [CrossRef]

90. Zheng, W.; Yang, B.; McLean, G.N. Linking organizational culture, structure, strategy, and organizational effectiveness: Mediating role of knowledge management. J. Bus. Res. 2010, 63, 763-771. [CrossRef]

91. Weick, K.E.; Quinn, R.E. Organizational change and development. Annu. Rev. Psychol. 1999, 50, $361-386$. [CrossRef] [PubMed]

92. Beycioglu, K.; Yasar Kondakci, D.; Jones, M.; Harris, A. Principals leading successful organisational change: Building social capital through disciplined professional collaboration. J. Organ. Chang. Manag. 2014, 27, 473-485.

93. Cunningham, I.; Hyman, J. Transforming the HRM vision into reality: The role of line managers and supervisors in implementing change. Empl. Relat. 1995, 17, 5-20. [CrossRef]

94. Finney, S.; Corbett, M. ERP implementation: A compilation and analysis of critical success factors. Bus. Process Manag. J. 2007, 13, 329-347. [CrossRef]

95. Brown, J.S.; Duguid, P. Organizational learning and communities-of-practice: Toward a unified view of working, learning, and innovation. Organ. Sci. 1991, 2, 40-57. [CrossRef]

96. Neves, P. Organizational cynicism: Spillover effects on supervisor-subordinate relationships and performance. Leadersh. Q. 2012, 23, 965-976. [CrossRef]

97. Nesterkin, D.A. Organizational change and psychological reactance. J. Organ. Chang. Manag. 2013, 26, 573-594. [CrossRef]

98. Bommer, W.H.; Rich, G.A.; Rubin, R.S. Changing attitudes about change: Longitudinal effects of transformational leader behavior on employee cynicism about organizational change. J. Organ. Behav. 2005, 26, 733-753. [CrossRef]

99. Li, F.; Zhou, F.; Leung, K. Expecting the worst: Moderating effects of social cynicism on the relationships between relationship conflict and negative affective reactions. J. Bus. Psychol. 2011, 26, 339-345. [CrossRef]

100. McNabb, D.E.; Sepic, F.T. Culture, climate, and total quality management: Measuring readiness for change. Pub. Product. Manag. Rev. 1995, 18, 369-385.

101. Brandes, P.; Castro, S.L.; James, M.S.; Martinez, A.D.; Matherly, T.A.; Ferris, G.R.; Hochwarter, W.A. The interactive effects of job insecurity and organizational cynicism on work effort following a layoff. J. Leadersh. Organ. Stud. 2008, 14, 233-248. [CrossRef] 
102. Hochwarter, W.A.; James, M.; Johnson, D.; Ferris, G.R. The interactive effects of politics perceptions and trait cynicism on work outcomes. J. Leadersh. Organ. Stud. 2004, 10, 44-57. [CrossRef]

103. Stevens, G.W. Toward a process-based approach of conceptualizing change readiness. J. Appl. Behav. Sci. 2013, 49, 333-360. [CrossRef]

104. Ancona, D.G.; Okhuysen, G.A.; Perlow, L.A. Taking time to integrate temporal research. Acad. Manag. Rev. 2001, 26, 512-529.

105. Zapf, D.; Dormann, C.; Frese, M. Longitudinal studies in organizational stress research: A review of the literature with reference to methodological issues. J. Occup. Health Psychol. 1996, 1, 145-169. [CrossRef] [PubMed]

106. Robson, C. Real World Research, 2nd ed.; Blackwell Publishing: Oxford, UK, 2002.

107. Dubé, L.; Paré, G. Rigor in information systems positivist case research: Current practices, trends, and recommendations. MIS Q. 2003, 27, 597-636. [CrossRef]

108. Darroch, J. Developing a measure of knowledge management behaviors and practices. J. Knowl. Manag. 2003, 7, 41-54. [CrossRef]

109. Holt, D.T.; Armenakis, A.; Field, H.S.; Harris, S.G. Readiness for Organizational Change. The Systematic Development of a Scale. J. Appl. Behav. Sci. 2007, 42, 232-255. [CrossRef]

110. Jerez-Gomez, P.; Cespedes-Lorente, J.; Valle-Cabrera, R. Organizational learning capability: A proposal of measurement. J. Bus. Res. 2005, 58, 715-725. [CrossRef]

111. Cole, M.S.; Bruch, H.; Vogel, B. Emotion as mediators of the relations between perceived supervisor support and psychological hardiness on employee cynicism. J. Organ. Behav. 2006, 27, 463-484. [CrossRef]

112. Madsen, S.R.; Miller, D.; John, C.R. Readiness for organizational change: Do organizational commitment and social relationships in the workplace make a difference? Hum. Resour. Dev. Q. 2005, 16, 213-233. [CrossRef]

113. Storey, J.D.; Taylor, J.E.; Siegmund, D. Strong control, conservative point estimation and simultaneous conservative consistency of false discovery rates: A unified approach. J. R. Stat. Soc. Ser. B 2004, 66, 187-205. [CrossRef]

114. Chen, M.-Y.; Huang, M.-J.; Cheng, Y.-C. Measuring knowledge management performance using a competitive perspective: An empirical study. Expert Syst. Appl. 2009, 36, 8449-8459. [CrossRef]

115. Venkatesh, V.; Davis, F.D. A theoretical extension of the technology acceptance model: Four longitudinal field studies. Manag. Sci. 2000, 46, 186-204. [CrossRef]

116. Kump, B.; Moskaliuk, J.; Cress, U.; Kimmerle, J. Cognitive foundations of organizational learning: Re-introducing the distinction between declarative and non-declarative knowledge. Front. Phychol. 2015, 6, 1489. [CrossRef] [PubMed]

117. Herteliu, C. Statistical Indicators System regarding Religious Phenomena. J. Study Relig. Ideologies 2007, 6, 115-131.

(C) 2017 by the authors. Licensee MDPI, Basel, Switzerland. This article is an open access article distributed under the terms and conditions of the Creative Commons Attribution (CC BY) license (http:/ / creativecommons.org/licenses/by/4.0/). 